Preprints of the

Max Planck Institute for

Research on Collective Goods

Bonn 2006/6

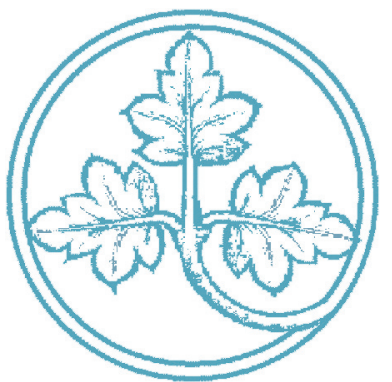

Distortionary Taxation and the Free-Rider Problem

Felix Bierbrauer

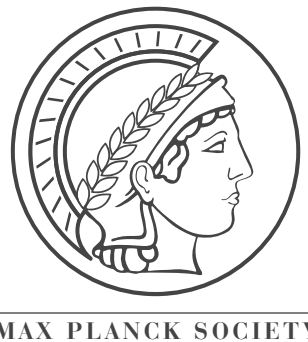




\section{Distortionary Taxation and the Free-Rider Problem}

Felix Bierbrauer

March 2006 


\title{
Distortionary Taxation and the Free-Rider Problem
}

\author{
Felix Bierbrauer* \\ Max Planck Institute for Research on Collective Goods, Bonn \\ and CDSEM, University of Mannheim
}

This version: March, 2006.

\begin{abstract}
This paper derives a version of the Samuelson rule, which takes not only the marginal costs of public funds into account but also the desirability of preference revelation. Under a linear income tax more able individuals suffer from a larger utility loss if taxes are raised to cover the cost of public good provision. This implies that these individuals are tempted to understate their valuation of the public good. Likewise, less productive individuals are inclined to exaggerate their valuation. These incentive concerns require the use of excessive taxes. They ensure a truthful revelation of preferences for the public good. Under an optimal utilitarian tax constitution, individuals are not granted influence on public good provision if the taxes needed to induce informative behavior are prohibitively high.
\end{abstract}

Keywords: Public Good Provision, Revelation of Preferences, Distortionary Taxation, Two-dimensional Heterogeneity.

JEL: D71, D82, H21, H41

\section{Introduction}

This paper derives the optimal utilitarian rule for public good provision under the premise that the costs are covered via distortionary taxation and that individuals have private information of their valuation of the public good. The existing literature has been concerned either with the impact of distortionary taxation or with the consequences of private information.

One branch of the literature is the theory of optimal taxation. It characterizes the optimal quantity of a public good by a modified Samuelson rule

\footnotetext{
${ }^{*}$ I am very grateful for comments and suggestions of Martin Hellwig, Thomas Gaube and Christoph Engel. I thank participants of the ENTER Jamboree 2004 in Barcelona, of the Theory Workshop at Mannheim University and the PET 2005 Meeting in Marseille.
} 
that equates the marginal costs of public funds and the sum of marginal utilities. ${ }^{1}$ In this framework, a problem of preference elicitation does not arise because the distribution of preferences in the economy is assumed to be common knowledge.

The second branch is the literature on the free-rider problem in public good provision, which studies the question what an optimal allocation of public goods looks like if individuals have private information of their preferences of a public good. ${ }^{2}$ This literature focusses on quasilinear environments in which the marginal disutility of having to pay for the public good is constant for all individuals. Hence, in this approach, payment obligations do not drive a wedge between marginal rates of substitution and marginal rates of transformation; that is, taxation is not distortionary.

The contribution of this paper is the derivation of a twice modified Samuelson rule that takes into account the welfare burden of distortionary taxes and, in addition, the desirability of preference revelation. This concern is not only driven by the desire to have a more complete theory. There is an interesting economic relationship between these two issues: Whether or not an individual is willing to reveal her valuation of a public good depends on the way she is treated by the tax system.

To see this, suppose that, as in this paper, a linear tax on income is used for public goods finance. Consequently, individuals with a higher level of income pay more taxes and hence contribute more to the cost of public good provision. When asked to report their preferences, these individuals compare their utility gain from public good provision to their additional tax burden. The fact that they have to contribute relatively large payments may imply that they refuse to reveal their true valuation of the public good. Instead, they choose their announcement such that they prevent the public good from being provided.

In more general terms, the tax system affects the willingness of individuals to reveal their valuation of a public good and is thus a potential source of incentive problems. This paper is a first attempt to discuss what an optimal response to these incentive problems looks like in a model which is as simple as possible: Individuals either have a low or a high level of earning ability. Likewise, valuations for the public good are either high or low. For the economy as a whole, there is uncertainty about the public goods preferences of the "rich" class and the "poor" class of agents, respectively. ${ }^{3}$ The decision

\footnotetext{
${ }^{1}$ Examples include Atkinson and Stern (1974), Wilson (1991), Boadway and Keen (1993), Nava et al. (1996), Sandmo (1998), Hellwig (2004) and Gaube (2000, 2005).

${ }^{2}$ The seminal contributions in the early literature are Clarke (1971), Groves (1973) and Green and Laffont (1977). See Hellwig (2003) or Norman (2004) for more recent treatments.

${ }^{3}$ The assumption that earning ability as well as public goods preferences can only take two values is made for reasons of tractability. The papers on two-dimensional screening problems by Armstrong and Rochet (1999) and Cremer et al. (2001) follow a similar modeling strategy.
} 
on public good provision is binary, i.e. the public good is either installed or not. ${ }^{4}$ Finally, the tax instrument used to finance public good provision is a linear tax on income.

An analysis of the free-rider problem under distortionary taxation can be conducted for all kinds of tax instruments, an affine linear income tax, a nonlinear income tax, a combination of direct and indirect tax instruments, etc. This paper focusses on a linear tax on income that is raised only to cover the cost of public good provision. This setup has the advantage of simplicity. In particular, it is easily seen how the tax system shapes individual assessments of the public good: The formal analysis proceeds under the assumption that individuals reduce their labor supply in response to an increased tax on income. Under this premise, it can be shown that individuals with a high level of earning ability suffer ceteris paribus from a larger utility loss if additional taxes are raised. Consequently the burden of taxation for a public good that is enjoyed by individuals of both classes is essentially carried by the "rich" class.

This generates the following pattern of incentive problems: More able individuals tend to understate their willingness to pay for the public good because they suffer more intensively from an increase of the tax revenue requirement. Analogously, less able individuals exaggerate when asked about their valuation because they don't feel a large utility burden from higher taxes.

As an example, think of the decision whether or not to use public money for the construction of a park. For the sake of the argument, suppose that the true state of the world is such that all inhabitants of the town realize the same utility gain if the park is available. Due to the tax system, however, the decision whether or not to install it creates conflicting interests between individuals with a high level of income and individuals with a low level of income. These interests govern the behavior of individuals in the revelation game and thus create an impediment for the acquisition of information on preferences.

The example illustrates that a pattern of incentive problems where less able individuals tend to exaggerate their preferences and the more able are too reserved is a plausible case. ${ }^{5}$ As a consequence, incentive compatibility constraints imply that the twice modified Samuelson rule relies on the use of excessive taxes, i.e. of taxes which are larger than actually needed to cover

\footnotetext{
${ }^{4}$ Bierbrauer and Sahm (2005) do not assume a perfect correlation of earning ability and public goods preferences, and they allow for a continuum of different provision levels.

${ }^{5} \mathrm{It}$ is, however, not the only conceivable constellation. The pattern is reversed under a non-linear income tax system, as shown in Bierbrauer (2005b). If the tax system generates, in addition, direct income transfers from "rich" to "poor" households, then less able individuals oppose public good provision more intensively. Tax revenues that are spent on public goods are not available for redistribution any more. This observation is assessed differently by the "rich" and the "poor".
} 
the cost of public good provision. These are used for two different reasons. Either they serve to make public good provision artificially expensive. This case arises if incentive compatibility conditions are needed to prevent less able individuals from exaggerating their valuation of the public good; that is, excessive taxes are used to make the public good less attractive for the less able class. Alternatively, if the more able individuals' temptation to understate their preferences causes an incentive problem, then excessive taxes can be used to make the non-provision of the public good less attractive.

If these excessive taxes become very high, then an optimal provision rule does not incorporate all pieces of information. Suppose for instance, that one needs to accompany public good provision with very high taxes in order to ensure a truthful statement from less able individuals on their valuation of the public good. Then, an optimal provision rule does not try to acquire information from them. Put differently, information that is too costly to obtain is neglected by the twice modified Samuelson rule.

More generally, the analysis shows that an optimal response to incentive problems takes one of the following forms. Either the tax system is distorted in order to ensure that valuable information on public goods preferences becomes available or the optimal provision rule is modified and does not require full information on the distribution of public goods preferences in the economy.

The remainder is organized as follows. The next section specifies the model. In Section 3, as a benchmark, the modified Samuelson rule is derived. Section 4 solves for the twice modified Samuelson rule. In Section 5, I discuss how the possibility of direct income transfers would affect the results. The last section contains concluding remarks. All proofs are in the appendix.

\section{The environment}

The economy consists of two classes of agents that are characterized by the earning ability levels $w_{1}$ and $w_{2}$, where $w_{2}>w_{1}$, i.e. class 2 agents are more productive. It is commonly known that there are equal shares of more and less productive individuals in the population. Individuals of class $t$, $t \in\{1,2\}$, have a common taste parameter $\theta_{t}$, which affects their valuation of a public good. Moreover, $\theta_{t}$ is private information of individuals who belong to class $t$.

The economy as a whole is subject to uncertainty about these taste parameters; $\theta_{1}$ and $\theta_{2}$ are taken to be the realizations of random variables $\tilde{\theta}_{1}$ and $\tilde{\theta}_{2}$. Both random variables can only take two values, $\theta_{L}$ and $\theta_{H}$, where $\theta_{L}<\theta_{H}$. Consequently, there are four possible states of the economy, depending on the preference parameters of class 1 and class 2 individuals, i.e. depending on the actual value of the vector $\left(\theta_{1}, \theta_{2}\right)$, where

$$
\left(\theta_{1}, \theta_{2}\right) \in\left\{\left(\theta_{L}, \theta_{L}\right),\left(\theta_{L}, \theta_{H}\right),\left(\theta_{H}, \theta_{L}\right),\left(\theta_{H}, \theta_{H}\right)\right\} .
$$


The utility function of individuals who belong to class $t$ is given by

$$
U_{t}=\theta_{t} Q+u(C)-v\left(\frac{Y}{w_{t}}\right) \text {. }
$$

$C$ denotes consumption of private goods, and $Y=L w_{t}$ denotes effective labor or income; that is, $w_{t}$ can be interpreted as a wage rate and $L$ denotes hours worked to generate income $Y$. Obviously, to achieve a given income $Y$, individuals with a lower wage have to work more. $Q \in\{0,1\}$ stands for a public project which is either installed or not. The functions $u$ and $v$ are strictly increasing and twice continuously differentiable. Moreover, $u$ is concave and $v$ is convex. In addition, those functions satisfy the following boundary condition, which ensures interior solutions to optimization problems: for all $w_{t}$ and all $C>0$, there exists $Y>0$, such that

$$
u^{\prime}(C)-\frac{1}{w_{t}} v^{\prime}\left(\frac{Y}{w_{t}}\right)=0 \text {. }
$$

I use a mechanism design approach to characterize admissible schemes of taxation and public good provision. An allocation rule specifies for each state $\left(\theta_{1}, \theta_{2}\right) \in\left\{\theta_{L}, \theta_{H}\right\}^{2}$ a decision on public good provision $Q\left(\theta_{1}, \theta_{2}\right)$ and a linear income tax rate $\tau\left(\theta_{1}, \theta_{2}\right)$. The revenues generated by this tax are used only to cover the cost of public good provision. ${ }^{6}$

An allocation rule has to satisfy a budget constraint $(B C)$. In every state $\left(\theta_{1}, \theta_{2}\right)$ the tax revenues from linear income taxation have to be sufficient to cover the cost $k$ of public good provision. Formally, for all $\left(\theta_{1}, \theta_{2}\right)$,

$$
\tau\left(\theta_{1}, \theta_{2}\right)\left[Y_{1}\left(\tau\left(\theta_{1}, \theta_{2}\right)\right)+Y_{2}\left(\tau\left(\theta_{1}, \theta_{2}\right)\right)\right] \geq k Q\left(\theta_{1}, \theta_{2}\right),
$$

where, for each $t \in\{1,2\}, Y_{t}\left(\tau\left(\theta_{1}, \theta_{2}\right)\right)$ is the utility maximizing level of effective labor supply for an individual who belongs to class $t$. More precisely, $Y_{t}\left(\tau\left(\theta_{1}, \theta_{2}\right)\right)$ is the unique solution of the following maximization problem:

$$
\max _{Y} u\left(\left(1-\tau\left(\theta_{1}, \theta_{2}\right) Y\right)\right)-v\left(\frac{Y}{w_{t}}\right) .
$$

The above budget constraint allows for a budget surplus, i.e. for tax rates which are higher than actually needed. It will become clear that, for incentive reasons, a deviation from budget balance may be desirable.

In addition to the budget constraint, an allocation rule has to satisfy incentive compatibility constraints (IC). These constraints ensure that individuals of either class are willing to reveal their taste parameter truthfully.

$$
\begin{aligned}
& \forall \theta_{1}, \forall \hat{\theta}_{1}, \forall \theta_{2}: \theta_{1} Q\left(\theta_{1}, \theta_{2}\right)+V_{1}\left(\theta_{1}, \theta_{2}\right) \geq \theta_{1} Q\left(\hat{\theta}_{1}, \theta_{2}\right)+V_{1}\left(\hat{\theta}_{1}, \theta_{2}\right), \\
& \forall \theta_{2}, \forall \hat{\theta}_{2}, \forall \theta_{1}: \theta_{2} Q\left(\theta_{1}, \theta_{2}\right)+V_{2}\left(\theta_{1}, \theta_{2}\right) \geq \theta_{2} Q\left(\theta_{1}, \hat{\theta}_{2}\right)+V_{2}\left(\theta_{1}, \hat{\theta}_{2}\right),
\end{aligned}
$$

\footnotetext{
${ }^{6}$ While this is the easiest way to introduce a distortionary tax instrument into the analysis, it is certainly not the only case of interest. The impact of this assumption and alternative specifications of the tax system are discussed in more detail in Section 5.
} 
where $V_{t}\left(\theta_{1}, \theta_{2}\right)$ denotes the indirect utility function of problem (2),

$$
V_{t}\left(\theta_{1}, \theta_{2}\right):=u\left(\left(1-\tau\left(\theta_{1}, \theta_{2}\right)\right) Y_{t}\left(\tau\left(\theta_{1}, \theta_{2}\right)\right)\right)-v\left(\frac{Y_{t}\left(\tau\left(\theta_{1}, \theta_{2}\right)\right)}{w_{t}}\right) .
$$

These incentive constraints are based on the presumption that, in the underlying revelation game, all individuals who belong to the same class make the same taste announcement. They ensure that the individuals of class $t$ are not better off under a joint collective lie about their taste parameter, whatever the collective taste announcement of individuals who belong to class $t^{\prime} \neq t$. Put differently, from the class perspective the truth is required to be a dominant strategy. ${ }^{7}$

A more extensive discussion of these incentive constraints can be found in Bierbrauer (2005a) and in Bierbrauer (2005b). These papers develop the notion of a collectively incentive compatible income tax mechanism. The collective incentive requirement addresses the following situation: Suppose that in order to figure out the actual state of the economy, a tax setting planner has to acquire information on individual valuations of a public good. Individuals may form coalitions in order to manipulate jointly the planner's perception of the state of the economy. As a consequence, the planner will discover the true state only if he decides on public good provision in a way which eliminates all incentives for manipulative collective actions. Obviously, the above incentive constraints, which address collective actions on the class level only, are a necessary condition for collective incentive compatibility. For a more precise statement of conditions under which this property is also sufficient, the reader is referred to Bierbrauer (2005a) and Bierbrauer (2005b). For the purpose of the present paper, I just note that those conditions are met.

The interpretation of these incentive constraints is as follows. The tax system shapes the views on public good provision of more and less productive individuals. Taking these interests into account, a decision on public good provision can use the actual taste parameter of any one group as an informational input only if these individuals are not made worse off if their private information becomes available.

An optimal allocation rule maximizes utilitarian welfare from an ex-ante perspective, defined as a hypothetical situation where the actual state of the economy $\left(\theta_{x}, \theta_{y}\right)$ is not yet known, where $x, y \in\{L, H\}$ indicate the taste realizations of class 1 and class 2 individuals, respectively. The objective function is a weighted average of the welfare levels $\left(W_{x y}\right)$, where

$$
W_{x y}:=\left(\theta_{x}+\theta_{y}\right) Q\left(\theta_{x}, \theta_{y}\right)+V_{1}\left(\theta_{x}, \theta_{y}\right)+V_{2}\left(\theta_{x}, \theta_{y}\right) .
$$

\footnotetext{
${ }^{7}$ The main advantage of implementation in dominant strategies is that the set of admissible allocations does not depend on assumptions about the prior beliefs of individuals. See e.g. Bergemann and Morris (2005); Chung and Ely (2004) or Kalai (2004).
} 
The probability weights are taken to be the prior beliefs of the tax setting planner, which are denoted $p:=\left(p_{L L}, p_{L H}, p_{H L}, p_{H H}\right)$, where $p_{L L}:=$ $\operatorname{prob}\left(\theta_{L}, \theta_{L}\right), p_{L H}:=\operatorname{prob}\left(\theta_{L}, \theta_{H}\right)$, etc. Expected welfare from the planner's ex ante perspective is accordingly given by

$$
E W:=p_{L L} W_{L L}+p_{L H} W_{L H}+p_{H L} W_{H L}+p_{H H} W_{H H} .
$$

Definition 1 The optimal utilitarian allocation rule solves the problem of choosing the functions $Q:\left(\theta_{1}, \theta_{2}\right) \mapsto Q\left(\theta_{1}, \theta_{2}\right)$ and $\tau:\left(\theta_{1}, \theta_{2}\right) \mapsto \tau\left(\theta_{1}, \theta_{2}\right)$ in order to maximize $E W$, subject to the budget constraints in (1) and the incentive compatibility constraints in (3).

\section{The complete information benchmark}

To understand the impact of the incentive compatibility conditions, this section discusses, as a benchmark, the allocation rule that would be chosen by an informed utilitarian planner, i.e. a planner who happens to know the actual value of $\left(\theta_{1}, \theta_{2}\right)$. For brevity, I refer to this outcome as the informed optimum.

Some more pieces of notation are helpful. Denote by $U^{*}\left(\tau, w_{t}\right)$ the indirect utility that is derived from consumption of private goods by an individual with earning ability $w_{t}$ who faces a linear income tax rate of $\tau$,

$$
U^{*}\left(\tau, w_{t}\right):=\max _{Y} u((1-\tau) Y)-v\left(\frac{Y}{w}\right) .
$$

Denote by $\tau_{k}$ the linear tax rate which ensures cost coverage in case of public good provision. This tax rate is implicitly defined by the following equation,

$$
\tau_{k}\left(Y_{1}\left(\tau_{k}\right)+Y_{2}\left(\tau_{k}\right)\right)=k .
$$

Let $\Delta U_{t}^{*}$ denote the private utility loss of a class $t$ individual as the tax rate increases from 0 to $\tau_{k}$,

$$
\Delta U_{t}^{*}:=U^{*}\left(0, w_{t}\right)-U^{*}\left(\tau_{k}, w_{t}\right) .
$$

Denote by $\Delta W_{p}^{*}$ the aggregate private utility loss, $\Delta W_{p}^{*}:=\Delta U_{1}^{*}+\Delta U_{2}^{*}$.

The informed optimum consists of a tax rule $\tau^{*}$ and a provision rule $Q^{*}$. The tax rule $\tau^{*}$ ensures a binding budget constraint,

$$
\tau^{*}\left(\theta_{1}, \theta_{2}\right)=\left\{\begin{array}{lll}
0, & \text { if } & Q^{*}=0 \\
\tau_{k}, & \text { if } & Q^{*}=1
\end{array}\right.
$$

Moreover, the informed planner chooses provision rule $Q^{*}$ such that the public good is installed as soon as the aggregate utility gain exceeds the aggregate private utility loss from higher tax rates,

$$
Q^{*}\left(\theta_{1}, \theta_{2}\right)= \begin{cases}0, & \text { if } \quad \Delta W_{p}^{*}>\theta_{1}+\theta_{2} \\ 1 & \text { otherwise }\end{cases}
$$


The informed optimum is completely characterized by the tax rule $\tau^{*}$ and the provision rule $Q^{*}$. However, the model outlined so far allows for a variety of different parameter constellations. For instance, if $\Delta W_{p}^{*}<2 \theta_{L}$, then $Q^{*}$ is such that the public good is provided in every state of the world, i.e. $Q^{*}\left(\theta_{1}, \theta_{2}\right)=1$ for all $\left(\theta_{1}, \theta_{2}\right)$. To avoid a lengthy discussion of each conceivable parameter constellation, I focus on a particular case.

Assumption 1 An informed planner chooses to install the public good in all states except state $\left(\theta_{L}, \theta_{L}\right):{ }^{8}$

$$
\theta_{H}+\theta_{L} \geq \Delta W_{p}^{*} \geq 2 \theta_{L} .
$$

For ease of reference, I denote by $Q^{i}: Q=0 \Longleftrightarrow\left(\theta_{1}, \theta_{2}\right)=\left(\theta_{L}, \theta_{L}\right)$, the provision rule chosen by an informed planner. Put differently, $Q^{i}$ is the modified Samuelson rule, which takes the distortions due to the tax rule $\tau^{*}$ into account but assumes that the information on public goods preferences just happens to be available.

\section{Conflicting interests induced by the informed optimum}

The informed optimum may give rise to conflicting views on the desirability of public good provision. For the sake of concreteness, suppose that

$$
\Delta U_{2}^{*}>\theta_{H}>\theta_{L}>\Delta U_{1}^{*} .
$$

In this scenario, for less productive individuals, the private utility loss is so small that, in all states, they are better off if the public good is installed. By contrast, the more productive suffer so heavily as the tax rate increases from 0 to $\tau_{k}$ that they are always worse off if the public good is installed. A clarification of the possible patterns of conflicting interests is important for an understanding of the impact of incentive compatibility constraints. Intuitively, if the scenario characterized by the inequalities in (4) arises, more productive individuals want to prevent the public good from being installed in every state and hence have an incentive to report a low taste realization, even if in fact their taste parameter is high. Likewise, the less able class wants to ensure provision and is tempted to report a high taste parameter in case of a low taste realization.

In the remainder of this section the possible parameter constellations of the model are characterized. It will become clear that the situation in (4) corresponds to a particular scenario, namely the one where the conflict on public

\footnotetext{
${ }^{8}$ Obviously, a parameter constellation such that $Q=1$ is desired in every (no) state of the world is not very interesting. Hence, the only alternative of interest is that $Q=0$ is preferred in states $\left(\theta_{L}, \theta_{H}\right)$ and $\left(\theta_{H}, \theta_{L}\right)$. An investigation of this case gives rise to an analysis analogous to the one presented below.
} 
good provision is most intense.

The following lemma is the key to an understanding of possible scenarios of conflicting interests. It shows that, for the more productive class of individuals, the private utility loss is larger if the tax rate $\tau$ goes up. In more technical terms, the lemma establishes a property of increasing differences according to which a larger productivity level translates into a larger private utility loss. The proof relies on the assumption that individuals decrease their labor supply in response to an increase in the tax rate.

Assumption 2 Labor supply is a decreasing function of $\tau:^{9}$

$$
\forall t \in\{1,2\}, \forall \tau \in\left[0,1\left[: \quad Y_{t}^{\prime}(\tau)<0 .\right.\right.
$$

Lemma 1 For any pair of tax rates $\underline{\tau}$ and $\bar{\tau}$ with $\bar{\tau}>\underline{\tau}$, if Assumption 2 holds, then:

$$
U^{*}\left(\underline{\tau}, w_{1}\right)-U^{*}\left(\bar{\tau}, w_{1}\right)<U^{*}\left(\underline{\tau}, w_{2}\right)-U^{*}\left(\bar{\tau}, w_{2}\right) .
$$

It is easily verified that individuals with a high earning ability choose, for any tax rate, a higher level of effective labor supply; that is, the more productive class has a higher level of income and thus pays more taxes. According to Lemma 1, this implies that ceteris paribus it is harder to convince the more productive class of individuals that the utility gain from public good provision justifies an increase of the tax rate. ${ }^{10}$

If combined with Lemma 1, Assumption 1 implies that the more able class is made worse off by public good provision in case of a low taste realization, i.e. if $\theta_{2}=\theta_{L}$. Likewise, less able individuals are better off if the public good is installed when $\theta_{1}=\theta_{H}$; that is,

$$
\Delta U_{2}^{*}>\theta_{L} \text { and } \theta_{H}>\Delta U_{1}^{*} .
$$

These inequalities in conjunction with Assumption 1 reduce the set of possible parameter constellations. The following three scenarios may arise.

$$
\begin{aligned}
& \text { Scenario 1: } \theta_{H} \geq \Delta U_{2}^{*}>\Delta U_{1}^{*} \geq \theta_{L}, \\
& \text { Scenario 2: } \theta_{H} \geq \Delta U_{2}^{*} \geq \theta_{L}>\Delta U_{1}^{*},
\end{aligned}
$$

\footnotetext{
${ }^{9}$ This assumption has been introduced by Sheshinski (1972) in a model of optimal linear income taxation and lump sum redistribution. Its role is further discussed in Hellwig (1986). An alternative assumption, which also yields the result of Lemma 1, is made in Persson and Tabellini (2000, Ch. 3). There income is exogenous, and utility is quasilinear in consumption.

${ }^{10}$ However, the proof relies on Assumption 2 according to which the substitution effect associated with a higher tax rate dominates the income effect. If this relation was reversed, the conclusion of Lemma 1 would be reversed as well. An analysis based on this alternative premise would have to follow the same line of reasoning as the one developed below.
} 


\section{Scenario 3: $\Delta U_{2}^{*}>\theta_{H}>\theta_{L}>\Delta U_{1}^{*}$.}

These inequalities are interpreted as follows.

Scenario 1: Individuals of any class, are better off by public good provision if their taste realization is high, $\theta_{t}=\theta_{H}$. They are worse off in case of a low taste realization, $\theta_{t}=\theta_{L}$. Scenario 1 hence gives rise to the statement that, at the informed optimum, willingness to pay for the public good is independent of earning ability, but depends only on the taste realization.

Scenario 2: As under Scenario 1, more productive individuals desire public good provision only if their utility gain is large, i.e. only if $\theta_{2}=\theta_{H}$. In contrast, less productive individuals, whose utility loss is smaller, benefit from provision in any state; that is, even if $\theta_{1}=\theta_{L}$.

Scenario 3: As under Scenario 2, less productive individuals always enjoy the public good. More able individuals, however, suffer from such a heavy utility loss that public good provision makes them worse off even if $\theta_{2}=\theta_{H}$. These Scenarios can be ordered with respect to the polarization of views on public good provision. Under Scenario 1 there is no polarization in the sense that both groups of individuals oppose public good provision if and only if their taste parameter is low. Under Scenario 3, the polarization is extreme; more productive individuals are against provision whatever their taste realization and less productive individuals always desire provision. Hence, in any state of the world, there is a conflict between more and less productive individuals. Scenario 2 is an intermediate case. While both groups prefer non-provision if their taste parameter is low (as under Scenario 1), the less productive desire public good provision even with a low taste parameter (as under Scenario 3).

\section{The twice modified Samuelson rule}

In this section the optimal tax rule and the optimal provision rule for the public good - i.e. the solution to the optimization problem in Definition 1 - is characterized for each parameter constellation of the model; that is, for each of the three scenarios defined in the previous section. The optimal allocation rule has to satisfy incentive compatibility. Hence, I call the optimal allocation a twice modified Samuelson rule because it takes into account the marginal costs of public funds under a linear income tax and, in addition, the desirability of preference revelation.

\subsection{Admissible provision rules}

The optimal allocation rule is derived via a two step procedure. The first step solves for an optimal tax rule, taking the provision rule for the public good as given. The second step determines the optimal provision rule. This 
approach is tractable because of the fact that the $I C$ constraints limit the number of admissible provision rules.

Lemma 2 Incentive compatible provision rules are increasing in both arguments, $\forall \theta_{1}: Q\left(\theta_{1}, \theta_{L}\right) \leq Q\left(\theta_{1}, \theta_{H}\right)$ and $\forall \theta_{2}: Q\left(\theta_{L}, \theta_{2}\right) \leq Q\left(\theta_{H}, \theta_{2}\right)$.

These monotonicity constraints imply that there are only six candidate provision rules. Provision rule $Q^{i}: Q=0 \Longleftrightarrow\left(\theta_{1}, \theta_{2}\right)=\left(\theta_{L}, \theta_{L}\right)$, which is part of the informed optimum, satisfies these constraints. The same is true for provision rule $Q^{i \prime}$, defined by $Q=1 \Longleftrightarrow\left(\theta_{1}, \theta_{2}\right)=\left(\theta_{H}, \theta_{H}\right)$, provision rule $Q^{1}$, which calls for public good provision if and only if class 1 individuals have a high taste parameter $Q^{1}: Q=1 \Longleftrightarrow \theta_{1}=\theta_{H}$, and the analogously defined provision rule $Q^{2}: Q=1 \Longleftrightarrow \theta_{2}=\theta_{H}$. Finally, the monotonicity constraints are trivially satisfied by the constant provision rules $Q \equiv 0$ and $Q \equiv 1$.

Any such provision rule can be interpreted in terms of the influence that is assigned to individuals of different classes. For instance, under provision rule $Q^{i}$, individuals of each class have a veto against $Q=0$ : whenever at least one class of individuals collectively announces a high taste realization, then the public good is provided. Likewise, under provision rule $Q^{i \prime}$, each class has a veto against $Q=1$. Under provision rule $Q^{1}$, the tax setting planner listens only to the preference announcement of the less able class. The more able have no influence on public good provision. Analogously, under $Q^{2}$, the decision on provision does not depend on the less able individuals' taste announcement. Finally, under $Q \equiv 0$ and $Q \equiv 1$, neither class has an impact.

\subsection{Does incentive compatibility always matter?}

As a first step, I characterize the circumstances under which the requirement of incentive compatibility indeed affects the choice of an optimal allocation rule. Obviously, incentive compatibility is not an issue if the informed optimum, as characterized by $\tau^{*}$ and $Q^{*}$, satisfies the incentive compatibility constraints in (3).

Under Assumption 1, the informed optimum has $Q^{*}=Q^{i}$. Using $\tau^{*}$ this implies that for class $t$, the informed optimum induces the following levels of indirect private utility,

$$
V_{t}\left(\theta_{1}, \theta_{2}\right)=\left\{\begin{array}{lll}
U^{*}\left(0, w_{t}\right), & \text { if } & \left(\theta_{1}, \theta_{2}\right)=\left(\theta_{L}, \theta_{L}\right) \\
U^{*}\left(\tau_{k}, w_{t}\right) & \text { otherwise. }
\end{array}\right.
$$

These expressions can be used to check whether or not the informed optimum satisfies the constraints in (3). It is easily verified that $I C$ holds if and only 
if, for any class $t$,

$$
\theta_{H} \geq \Delta U_{t}^{*} \geq \theta_{L} .
$$

This chain of inequalities is satisfied if and and only if Scenario 1 applies. This proves the following proposition.

Proposition 1 The informed optimum is incentive compatible if and only if Scenario 1 applies, i.e. if and only if willingness to pay for the public good is independent of earning ability.

Thus, there is indeed a parameter constellation where the tax setting planner gets the information on taste parameters for free; that is, without a welfare loss due to binding incentive compatibility constraints. This is the case if all high ability agents and all low ability agents want the public good to be installed only in case of a high taste realization. Put differently, whether or not an individual prefers $Q=1$ over $Q=0$ depends only on the taste realization but not on the ability level.

Note, however, that the absence of incentive problems is not the same as the absence of conflicting interests. To see this, suppose that the actual state of the economy is $\left(\theta_{L}, \theta_{H}\right)$. In this case, the less able individuals prefer $Q=0$, while the more productive prefer $Q=1$. However, despite those conflicting views, neither class has an incentive to hide its true taste realization. A false announcement would not yield a preferred outcome.

Proposition 1 characterizes the optimal allocation rule under Scenario 1. As the informed optimum is incentive compatible, the modified Samuelson rule and the twice modified Samuelson rule coincide. The analysis of Scenarios 2 and 3 shows that this is not generally the case.

\subsection{Scenario 2}

The analysis proceeds in two steps. Recall that an informed utilitarian planner would choose provision rule $Q^{i}$. I first indicate what taxes a utilitarian planner chooses, given that this provision rule has to be implemented. Then, I analyze whether this provision rule remains part of an optimal allocation rule under incentive constraints.

\subsubsection{Optimal taxes for provision rule $Q^{i}$ under Scenario 2}

Under Scenario 2, incentive problems arise for the following reason. Given that provision rule $Q^{i}$ is chosen or implementation and taxes are such that the budget constraint binds, less able individuals will never admit a low taste realization. Hence, if the planner sticks to provision rule $Q^{i}$, a deviation from budget balance becomes unavoidable. I will now solve for the optimal 
deviation.

I first derive a concise statement of the planner's problem. From substituting $Q^{i}$ into the incentive compatibility constraints in (3), one finds that incentive compatibility for the less able class requires that

$$
\theta_{H} \geq V_{1}\left(\theta_{L}, \theta_{L}\right)-V_{1}\left(\theta_{H}, \theta_{L}\right) \geq \theta_{L}, \quad V_{1}\left(\theta_{L}, \theta_{H}\right)=V_{1}\left(\theta_{H}, \theta_{H}\right) .
$$

Similarly, the incentive constraints for the more productive are

$$
\theta_{H} \geq V_{2}\left(\theta_{L}, \theta_{L}\right)-V_{1}\left(\theta_{L}, \theta_{H}\right) \geq \theta_{L}, \quad V_{2}\left(\theta_{H}, \theta_{L}\right)=V_{2}\left(\theta_{H}, \theta_{H}\right) .
$$

These incentive constraints imply that whenever $Q=1$ the same tax rate has to be used to cover the cost of provision, $\tau\left(\theta_{H}, \theta_{H}\right)=\tau\left(\theta_{L}, \theta_{H}\right)=$ $\tau\left(\theta_{H}, \theta_{L}\right) .{ }^{11}$ This tax rate is henceforth called $\bar{\tau}$, i.e.

$$
\bar{\tau}:=\tau\left(\theta_{H}, \theta_{H}\right)=\tau\left(\theta_{L}, \theta_{H}\right)=\tau\left(\theta_{H}, \theta_{L}\right) .
$$

Analogously, define $\underline{\tau}:=\tau\left(\theta_{L}, \theta_{L}\right)$. Using those tax rates, the incentive constraints for any class $t$ can be rewritten as:

$$
\theta_{H} \geq U^{*}\left(\underline{\tau}, w_{t}\right)-U^{*}\left(\bar{\tau}, w_{t}\right) \geq \theta_{L}
$$

In addition, from the property of increasing differences, the private utility loss due to higher taxation is larger for individuals of class 2 ,

$$
U^{*}\left(\underline{\tau}, w_{2}\right)-U^{*}\left(\bar{\tau}, w_{2}\right)>U^{*}\left(\underline{\tau}, w_{1}\right)-U^{*}\left(\bar{\tau}, w_{1}\right) .
$$

Consequently, the planner only has to take the constraints $\theta_{H} \geq U^{*}\left(\underline{\tau}, w_{2}\right)-$ $U^{*}\left(\bar{\tau}, w_{2}\right)$ and $U^{*}\left(\underline{\tau}, w_{1}\right)-U^{*}\left(\bar{\tau}, w_{1}\right) \geq \theta_{L}$ into account.

In other words, the observation that it is harder to convince the more able class that the public good should be installed implies that the $I C$ conditions can be simplified. IC holds whenever the "poor" are willing to admit a low valuation of the public good and the "rich" are willing to admit a high valuation.

The planner's problem can now be stated in the following way: Denote by $W_{p}(\tau):=U^{*}\left(\tau, w_{1}\right)+U^{*}\left(\tau, w_{2}\right)$ the welfare contribution of aggregate private utility, given a tax rate of $\tau$. An optimal choice of $\underline{\tau}$ and $\bar{\tau}$ solves the following problem, referred to as Problem $P$ :

$$
\begin{array}{lll}
\max _{\bar{\tau}, \underline{\tau}} & p_{L L} W_{p}(\underline{\tau})+\left(1-p_{L L}\right) W_{p}(\bar{\tau}) & \\
\text { s.t. } & \underline{\tau} \geq 0, \quad \bar{\tau} \geq \tau_{k} & (\mathrm{BC}), \\
& \theta_{H} \geq U^{*}\left(\underline{\tau}, w_{2}\right)-U^{*}\left(\bar{\tau}, w_{2}\right) & \left(\mathrm{IC}_{2}\right), \\
& U^{*}\left(\underline{\tau}, w_{1}\right)-U^{*}\left(\bar{\tau}, w_{1}\right) \geq \theta_{L} \quad\left(\mathrm{IC}_{1}\right) .
\end{array}
$$

\footnotetext{
11 As the function $U^{*}\left(\tau, w_{t}\right)$ is strictly decreasing in $\tau$, the constraint $V_{1}\left(\theta_{L}, \theta_{H}\right)=$ $V_{1}\left(\theta_{H}, \theta_{H}\right)$ implies $\tau\left(\theta_{L}, \theta_{H}\right)=\tau\left(\theta_{H}, \theta_{H}\right)$ and $V_{2}\left(\theta_{H}, \theta_{L}\right)=V_{2}\left(\theta_{H}, \theta_{H}\right)$ gives $\tau\left(\theta_{H}, \theta_{L}\right)=$ $\tau\left(\theta_{H}, \theta_{H}\right)$.
} 
I denote by $\underline{\tau}^{* *}$ and $\bar{\tau}^{* *}$ the second best tax rates, which solve $P$. In addition, denote by $\tau_{1 L}$ the tax rate which satisfies

$$
U^{*}\left(0, w_{1}\right)-U^{*}\left(\tau_{1 L}, w_{1}\right)=\theta_{L} .
$$

$\tau_{1 L}$ makes less able individuals with $\theta_{L}$ indifferent with respect to public good provision, given that $\underline{\tau}=0$. Note that by the definition of Scenario 1, $\tau_{1 L}>\tau_{k}$.

\section{Lemma 3}

a) If $\theta_{H} \geq U^{*}\left(0, w_{2}\right)-U^{*}\left(\tau_{1 L}, w_{2}\right)$, then $\underline{\tau}^{* *}=0$ and $\bar{\tau}^{* *}=\tau_{1 L}$.

b) If $\theta_{H}<U^{*}\left(0, w_{2}\right)-U^{*}\left(\tau_{1 L}, w_{2}\right)$, a solution to the planner's problem exists only if there are tax rates such that $\mathrm{IC}_{1}$ and $\mathrm{IC}_{2}$ are binding. Furthermore, if a solution exists, then $\underline{\tau}^{* *}>0$ and $\bar{\tau}^{* *}>\tau_{k}$.

Under Scenario 2, the less productive class has to be prevented from announcing a high taste parameter if in fact their taste parameter is low. In order to fix this incentive problem, the outcome $Q=1$ is made less attractive by excessive taxation, i.e. the tax $\bar{\tau}^{* *}$ exceeds the level $\tau_{k}$, which would be sufficient to cover the cost of provision.

However, this excessive tax rate may generate a new incentive problem: if the public good is made less attractive, then one might end up in a situation where more productive individuals are no longer willing to admit a high valuation of the public good.

There are two possible cases. In case of a modest incentive problem - i.e. if $\theta_{H} \geq U^{*}\left(0, w_{2}\right)-U^{*}\left(\tau_{1 L}, w_{2}\right)$ - the more able still prefer $Q=1$ under an excessive level of $\bar{\tau}$. In contrast, if incentive problems are severe, then $Q^{i}$ is implementable only if both incentive constraints are binding. However, a pair of tax rates such that both incentive constraints are binding need not exist. ${ }^{12}$ If those tax rates do not exist, then, under a severe incentive problem, provision rule $Q^{i}$ is not implementable.

In the next subsection I analyze whether the planner is indeed willing to choose these excessive tax rates in order to be able to implement provision rule $Q^{i}$.

\subsubsection{The optimal provision rule under Scenario 2}

As has just been shown, if the planner wants to implement $Q^{i}$, then he has to accept the need to waste tax revenues, because the less able class loves the public good too intensively. More generally, such a waste of tax revenues

\footnotetext{
${ }^{12}$ For standard examples of functional forms - Cobb Douglas utility in logarithmic formulation or isoelastic components of private utility - those tax rates do not exist.
} 
becomes unavoidable if the decision on provision is made dependent on the taste announcement of the less able class. This is true for provision rules $Q^{i}, Q^{i \prime}$ and $Q^{1}$.

There are, however, provision rules, which do not require excessive taxes. Under provision rules $Q \equiv 0$ and $Q \equiv 1$, the decision on provision is not state dependent. Consequently, there is no need to communicate and hence no need for excessive taxes in order to ensure truth-telling. Under provision rule $Q^{2}$, the planner only has to ask only the more able class about their preferences. They want to induce public good provision if and only if $\theta_{2}=\theta_{H}$. This implies that $Q^{2}$ can also be implemented without having to rely on excessive taxes.

A utilitarian planner faces a tradeoff. Either he sticks to provision rule $Q^{i}$ and has to burn money, or he decides not to burn money but deviates from the provision rule that is part of the informed optimum. The following proposition shows how a utilitarian planner deals with this issue, depending on the intensity of incentive problems and his prior.

More precisely, the proposition summarizes the results from the following exercise: For each candidate provision - i.e. for each provision rule in the set $\left\{Q^{i}, Q^{i^{\prime}}, Q^{1}, Q^{2}, Q \equiv 0, Q \equiv 0\right\}$ - solve for the optimal tax rates that implement this provision rule under budget and incentive constraints; that is, for each candidate provision rule, solve the same kind of optimization problem as the one discussed in subsection 4.3.1 for provision rule $Q^{i}$. The solution to each optimization problem allows the computation of the resulting welfare levels, which I denote by $E W^{i}, E W^{i^{\prime}}, E W^{1}, E W^{2}, E W^{Q \equiv 0}$ and $E W^{Q \equiv 1}$, respectively. A comparison of these welfare levels then determines the optimal provision rule under budget as well as incentive constraints.

The welfare maximizing provision rule depends on the prior beliefs; that is, on the probability weights that are used in the computation of expected welfare levels. I say that a provision rule can be supported if there exists a vector of prior beliefs $p$ such that this provision rule turns out to be welfare maximizing.

\section{Proposition 2}

i) Suppose the incentive problem is modest, i.e. $\theta_{H} \geq U^{*}\left(0, w_{2}\right)-$ $U^{*}\left(\tau_{1 L}, w_{2}\right)$. Then $Q^{2}, Q^{i}$ and $Q \equiv 1$ can be supported. ${ }^{13}$

ii) Suppose the incentive problem is severe, $\theta_{H}<U^{*}\left(0, w_{2}\right)-U^{*}\left(\tau_{1 L}, w_{2}\right)$. Then $Q^{2}$ and $Q \equiv 1$ can be supported.

Proposition 2 shows that, in case of a severe incentive problem - i.e. if $\theta_{H}<U^{*}\left(0, w_{2}\right)-U^{*}\left(\tau_{1 L}, w_{2}\right)-$ provision rule $Q^{i}$ is never chosen. Even

\footnotetext{
${ }^{13}$ For the special case $\theta_{H}=U^{*}\left(0, w_{2}\right)-U^{*}\left(\tau_{1 L}, w_{2}\right)$, provision rules $Q^{1}$ and $Q^{i}$ yield the same level of expected utilitarian welfare. Otherwise $Q^{i}$ is strictly superior.
} 
if tax rates exist under which this rule is implementable, the planner will avoid the welfare burden of two binding incentive constraints. This shows that incentive constraints may heavily affect optimal policy: provision rule $Q^{i}$ either becomes infeasible or undesirable.

In case of a severe incentive problem, only provision rules $Q^{2}$ and $Q \equiv 1$, which avoid excessive taxation by not giving any influence to the less able class, are candidates for maximizing expected utilitarian welfare. ${ }^{14}$ In contrast, under modest incentive problems, the planner may stick to provision rule $Q^{i}$, i.e. the burden of excessive taxation is not necessarily prohibitive. ${ }^{15}$ In particular, these considerations show that the the second modification of the Samuelson rule can go either way. Under $Q^{2}$ there are less states of the economy in which the public good is installed relative to $Q^{i}$. Under $Q \equiv 1$ however, the public good is provided in every state. Hence, it depends on the prior beliefs of the planner whether there is "underprovision" or "overprovision" relative to $Q^{i}$.

\subsection{Scenario 3}

Under Scenario 3, the incentive problem known from Scenario 2 - i.e. that under budget balance, the less able will never admit a low valuation because they want to ensure $Q=1$ - is accompanied by another incentive problem that is due to the more able class of individuals. Under budget balance, they will not admit a high valuation because they hate having to pay for the public good. Consequently, a case of modest incentive problems is not possible under Scenario 3; i.e. Scenario 3 is essentially equivalent to Scenario 2 with a severe incentive problem.

To see this, recall that the incentive problem caused by the less able requires that the public good becomes less attractive. This requires an excessive tax rate whenever the public good is installed. By contrast, the incentive problem caused by the more able class calls for an excessive tax rate that makes non-provision a less attractive outcome. Those two incentive problems aggravate each other: Trying to fix the incentive problem for the less able class makes the outcome $Q=1$ less attractive, and this implies that it becomes even harder to make the more able class willing to admit a high taste realization.

Consequently, whenever a provision rule is chosen that gives influence to both classes - recall that this is the case under $Q^{i}$ and $Q^{i \prime}$ - one ends up

\footnotetext{
${ }^{14}$ Which of them is superior depends on the likelihood of the states in which they implement a different allocation. By definition of Scenario $1, Q^{2}$ yields ex post the higher welfare level if $\left(\theta_{1}, \theta_{2}\right)=\left(\theta_{L}, \theta_{L}\right)$, rule $Q \equiv 1$ is superior if $\left(\theta_{1}, \theta_{2}\right)=\left(\theta_{H}, \theta_{L}\right)$.

${ }^{15}$ To see why $Q^{i}$ comes in as an additional candidate for optimal policy, suppose that $p_{L L}$ is sufficiently large in the sense that $Q^{2}$ yields a higher expected welfare level than $Q \equiv 1$. Ex post, rule $Q^{i}$ gives a higher welfare level as compared to rule $Q^{2}$ if $\left(\theta_{1}, \theta_{2}\right)=$ $\left(\theta_{H}, \theta_{L}\right)$, and rule $Q^{2}$ is more attractive if $\theta_{2}=\theta_{H}$. Hence, to ensure optimality of rule $Q^{i}$ conditionally on $\left(\theta_{1}, \theta_{2}\right) \neq\left(\theta_{L}, \theta_{L}\right)$, the probability that $\theta_{2}=\theta_{H}$ must be small.
} 
with two binding incentive constraints. As has been discussed in the previous subsection this may imply that these provision rules can no longer be implemented. This is the case if no pair of tax rates exists that makes the incentive constraints of both classes binding.

One easily verifies, however, that even if implementation is possible, those provision rules become undesirable. Put differently, there do not exist prior beliefs that support $Q^{i}$ or $Q^{i \prime}$ under Scenario 3. The reason has already been discussed in the previous subsection. The welfare burden of two excessive tax rates becomes prohibitive. For instance, one can show that the planner prefers to communicate with only one class of individuals; that is, to choose $Q^{1}$ or $Q^{2}$ instead. Even though this implies that some information is lost, it requires only one excessive tax rate. The total effect is a larger level of expected utilitarian welfare.

\section{Robustness}

Up to now, it has been assumed that there are only two alternative uses of the proceeds from linear taxation: covering the cost of public good provision; and "waste" for incentive reasons. This raises the question how far the results depend on these assumptions: e.g. what would the the analysis look like if direct income transfers were allowed and excessive tax revenues could be returned to the agents? A further concern is the degree to which results rely on the fact that taxation is linear. Below, I report on a series of exercises that study the robustness of this paper's results.

I first argue that the linear tax on income is necessary if a higher tax revenue requirement is to do greater harm to the more productive. To see this, suppose that taxation is non-linear and that direct income transfers are allowed as in Bierbrauer (2005b). ${ }^{16}$ In this setting, an increased revenue requirement, due to public good provision, yields a larger private utility loss for less able individuals. The property of increasing differences, established in Lemma 1, is hence replaced by decreasing differences. The underlying reason is as follows: An optimal non-linear income tax is an arrangement of redistribution under incentive constraints. As shown in Bierbrauer (2005b), this implies that the more able class who already finances the transfer system cannot be used to generate additional tax revenues for the public good. In addition, it is proven that, even though incentive requirements imply that a utilitarian planner has to deviate from the complete information benchmark, the more flexible instrument of a non-linear income tax makes it possible to avoid a waste of tax revenues.

Similar results can be obtained in the following environment: the linear income tax rate $\tau$ is not only raised to cover the cost of public good provision,

\footnotetext{
${ }^{16}$ The problem of preference revelation is introduced into the framework of a two-class economy, as, for instance, analyzed in Stiglitz (1982) or Boadway and Keen (1993).
} 
but also in order to finance a lump sum transfer $\alpha$, which is equal for all individuals in the economy. If both $\tau$ and $\alpha$ are set optimally according to a utilitarian welfare function, ${ }^{17}$ the need to finance a public project has two opposing effects. It leads to an increase of $\tau$ and to a reduction of $\alpha$. It is easy to find examples where the second effect dominates, ${ }^{18}$ implying, once again, that one has decreasing differences. Hence, the mere fact that a linear tax system is in operation does not imply that the rich are going to suffer relatively more if additional tax revenues are needed. This effect will occur only if redistribution is not reduced too much in response to public good provision.

To sum up, the discussion shows that the analysis of this paper is applicable only if the level of income transfers is kept fixed and public good provision is financed by additional linear taxes.

\section{Concluding Remarks}

An important theme in political economics is the question whether or not political competition induces efficient outcomes. ${ }^{19}$ Polo (1998) and Svensson (2000) study this question in the context of a probabilistic voting model. The authors show that equilibrium rents, defined as an excess of tax revenues over the cost of public good provision, are positive. This observation seems to support the view that political competition yields undesirable outcomes.

The present paper, by contrast, does not attempt to model the outcome of the political process in a somewhat realistic manner. Instead, the paper describes what an ideal arrangement looks like under the assumptions that there exist two groups of agents and that a policy decision has to based on their behavior in a revelation game. It turns out that a constrained efficient allocation may involve a waste of tax revenues. Burning money may be a valuable policy option in order to ensure that private information becomes available for public decision making.

This sheds a different light on the results mentioned above. The mere fact that an equilibrium outcome of some political game involves a budget surplus cannot be taken as evidence of inefficiency. Such a conclusion requires the identification of the constrained efficient allocations under all relevant informational, institutional and technological restrictions. In particular, the

\footnotetext{
${ }^{17}$ This model has been studied in more detail by Sheshinski (1972) and Hellwig (1986).

${ }^{18}$ Suppose that $u(x)=\ln (x)$ and $v(x)=x^{\gamma}$. For $\gamma \rightarrow 1$, the optimal linear tax rate becomes independent of the revenue requirement $k Q\left(\theta_{1}, \theta_{2}\right)$; that is, the public good is just crowding out the income transfer $\alpha$.

${ }^{19}$ Alternative views on that issue are associated with the labels of Virginia, for emphasis on inefficiencies induced by rent-seeking, and Chicago, for the idea that competition among politicians leaves no room for rent-extraction. See Coate and Morris (1995) and Persson and Tabellini (2000) for further discussion.
} 
present paper suggests that excessive tax revenues may not result from the deficiencies political competition but from the fact that the set of policy instruments is rather limited.

\section{A Appendix}

Proof of Lemma 1: Straightforward calculations yield

$$
\begin{aligned}
Y_{t}^{\prime}(\tau) & =\frac{u^{\prime}\left((1-\tau) Y_{t}(\tau)\right)+(1-\tau) Y_{t}(\tau) u^{\prime \prime}\left((1-\tau) Y_{t}(\tau)\right)}{(1-\tau)^{2} u^{\prime \prime}\left((1-\tau) Y_{t}(\tau)\right)-w_{t}^{-2} v^{\prime \prime}\left(Y_{t}(\tau) / w_{t}\right)}, \text { and } \\
\frac{\partial^{2} U^{*}\left(\tau, w_{t}\right)}{\partial \tau \partial w_{t}} & =\frac{Y_{t}^{\prime}(\tau)}{w_{t}^{2}}\left[v^{\prime}\left(\frac{Y_{t}(\tau)}{w_{t}}\right)+\frac{Y_{t}(\tau)}{w_{t}} v^{\prime \prime}\left(\frac{Y_{t}(\tau)}{w_{t}}\right)\right] .
\end{aligned}
$$

If this cross derivative is negative, then preferences satisfy the property of increasing differences.

Proof of Lemma 2: The monotonicity of admissible provision rules is derived as follows: consider for example the two incentive compatibility constraints for class 1 , given that $\theta_{2}=\theta_{L}$ :

$$
\begin{aligned}
& \text { if } \theta_{1}=\theta_{L}: \quad \theta_{L} Q\left(\theta_{L}, \theta_{L}\right)+V_{1}\left(\theta_{L}, \theta_{L}\right) \geq \theta_{L} Q\left(\theta_{H}, \theta_{L}\right)+V_{1}\left(\theta_{H}, \theta_{L}\right), \\
& \text { if } \theta_{1}=\theta_{H}: \quad \theta_{H} Q\left(\theta_{H}, \theta_{L}\right)+V_{1}\left(\theta_{H}, \theta_{L}\right) \geq \theta_{H} Q\left(\theta_{L}, \theta_{L}\right)+V_{1}\left(\theta_{L}, \theta_{L}\right) .
\end{aligned}
$$

Adding up these inequalities gives $Q\left(\theta_{H}, \theta_{L}\right) \geq Q\left(\theta_{L}, \theta_{L}\right)$. Similarly, one derives the constraints $Q\left(\theta_{L}, \theta_{H}\right) \geq Q\left(\theta_{L}, \theta_{L}\right), Q\left(\theta_{H}, \theta_{H}\right) \geq Q\left(\theta_{H}, \theta_{L}\right)$ and $Q\left(\theta_{H}, \theta_{H}\right) \geq Q\left(\theta_{L}, \theta_{H}\right)$.

\section{Proof of Lemma 3:}

a) Suppose $\theta_{H} \geq U^{*}\left(0, w_{2}\right)-U^{*}\left(\tau_{1 L}, w_{2}\right)$. Consider the relaxed problem, which ignores $\mathrm{IC}_{2}$. At a solution, it has to be true that $\tau^{* *}=0$. Otherwise $\tau^{* *}$ could be reduced in a feasible and incentive compatible manner, thereby contradicting optimality. The optimal level of $\bar{\tau}$ then has to ensure that $\mathrm{IC}_{1}$ is binding. Hence, $\bar{\tau}^{* *}=\tau_{1 L}$. The assumption $\theta_{H} \geq U^{*}\left(0, w_{2}\right)-U^{*}\left(\tau_{1 L}, w_{2}\right)$ implies that $\mathrm{IC}_{2}$ can indeed be ignored.

b) Let $\theta_{H}<U^{*}\left(0, w_{2}\right)-U^{*}\left(\tau_{1 L}, w_{2}\right)$, and suppose a solution exists. Let $\tau_{2 H}$ be the tax rate that is implicitly defined by the equation $\theta_{H}=$ 
$U^{*}\left(0, w_{2}\right)-U^{*}\left(\tau_{2 H}, w_{2}\right)$. Again, by definition of Scenario $1, \tau_{2 H}>\tau_{k}$. Note that $\theta_{H}<U^{*}\left(0, w_{2}\right)-U^{*}\left(\tau_{1 L}, w_{2}\right)$ implies $\tau_{2 H}<\tau_{1 L}$.

i) It must be the case that $\bar{\tau}^{* *}>\tau_{k}$. Suppose, to the contrary, that $\bar{\tau}^{* *}=\tau_{k}$. Then $\mathrm{IC}_{1}$ is violated. To see this, note that $\bar{\tau}^{* *}=\tau_{k}$ implies

$$
U^{*}\left(\underline{\tau}^{* *}, w_{1}\right)-U^{*}\left(\bar{\tau}^{* *}, w_{1}\right) \leq \Delta U_{1}^{*}<\theta_{L} .
$$

ii) It must be the case that $\tau^{* *}>0$. Suppose, to the contrary, that $\underline{\tau}^{* *}=0$. Then $\mathrm{IC}_{1}$ implies $\bar{\tau}^{* *} \geq \tau_{1 L}$, and $\mathrm{IC}_{2}$ implies $\bar{\tau}^{* *} \leq \tau_{2 H}$, contradicting $\tau_{2 H}<\tau_{1 L}$.

iii) At least one (IC) constraint has to be binding. Otherwise - with $\underline{\tau}^{* *}>0$ and $\bar{\tau}^{* *}>\tau_{k}$ - both tax rates could be reduced in a feasible and incentive compatible manner. To see that both (IC) constraints have to be binding, suppose, for instance, that, at an optimum, $\mathrm{IC}_{2}$ binds and $\mathrm{IC}_{1}$ does not. Then, both tax rates could be reduced in a feasible and incentive compatible manner - keeping the equality in the constraint for class 2 , while not violating the one for class 1 - thereby increasing utilitarian welfare.

Proof of Proposition 2: First, optimal welfare $E W^{q}$ for each provision rule is derived, where the superscript $q$ refers to the provision rule. In the second step, those welfare levels are compared to determine the optimal provision rule.

Rule $Q \equiv 0: E W^{Q \equiv 0}=U^{*}\left(0, w_{1}\right)+U^{*}\left(0, w_{2}\right)$.

Rule $Q^{i \prime}$ : Along the same lines as for Problem $P$, one derives that the planner has to solve the following problem if $Q^{i \prime}$ is chosen:

$$
\begin{array}{lll}
\max _{\bar{\tau}, \underline{\tau}} & \left(1-p_{H H}\right) W_{p}(\underline{\tau})+p_{H H} W_{p}(\bar{\tau}) & \\
\text { s.t. } & & (\mathrm{BC}), \\
& \underline{\tau} \geq 0, \quad \bar{\tau} \geq \tau_{k} & \left(\mathrm{IC}_{2}\right), \\
& \theta_{H} \geq U^{*}\left(\underline{\tau}, w_{2}\right)-U^{*}\left(\bar{\tau}, w_{2}\right) & \\
& U^{*}\left(\underline{\tau}, w_{1}\right)-U^{*}\left(\bar{\tau}, w_{1}\right) \geq \theta_{L} & \left(\mathrm{IC}_{1}\right) .
\end{array}
$$

The solution to this problem has been characterized in Lemma 3 . If $\theta_{H} \geq$ 
$U^{*}\left(0, w_{2}\right)-U^{*}\left(\tau_{1 L}, w_{2}\right)$, then expected welfare is given as:

$$
\begin{aligned}
E W^{i^{\prime}}= & \left(1-p_{H H}\right)\left(U^{*}\left(0, w_{1}\right)+U^{*}\left(0, w_{2}\right)\right) \\
& +p_{H H}\left(2 \theta_{H}+U^{*}\left(\tau_{1 L}, w_{1}\right)+U^{*}\left(\tau_{1 L}, w_{2}\right)\right) .
\end{aligned}
$$

If $\theta_{H}<U^{*}\left(0, w_{2}\right)-U^{*}\left(\tau_{1 L}, w_{2}\right)$, either rule $Q^{i \prime}$ cannot be implemented or the optimal combination of $\underline{\tau}$ and $\bar{\tau}$, for which both $I C$ constraints are binding, is chosen. Denote these as $\tau_{L L}$ and $\tau_{H H}$, respectively. Then,

$$
\begin{aligned}
E W^{i^{\prime}}= & \left(1-p_{H H}\right)\left(U^{*}\left(\tau_{L L}, w_{1}\right)+U^{*}\left(\tau_{L L}, w_{2}\right)\right) \\
& +p_{H H}\left(2 \theta_{H}+U^{*}\left(\tau_{H H}, w_{1}\right)+U^{*}\left(\tau_{H H}, w_{2}\right)\right) .
\end{aligned}
$$

Rule $Q^{1}$ : Under provision rule $Q^{1},\left(\mathrm{IC}_{2}\right)$ requires $V_{2}\left(\theta_{L}, \theta_{H}\right)=V_{2}\left(\theta_{L}, \theta_{L}\right)$ and $V_{2}\left(\theta_{H}, \theta_{H}\right)=V_{2}\left(\theta_{H}, \theta_{L}\right)$, or equivalently $\underline{\tau}:=\tau\left(\theta_{L}, \theta_{L}\right)=\tau\left(\theta_{L}, \theta_{H}\right)$ and $\bar{\tau}:=\tau\left(\theta_{H}, \theta_{H}\right)=\tau\left(\theta_{H}, \theta_{L}\right)$. The planner's problem becomes:

$$
\begin{array}{lll}
\max _{\bar{\tau}, \underline{\tau}} & \left(p_{L L}+p_{L H}\right) W_{p}(\underline{\tau})+\left(p_{H L}+p_{H H}\right) W_{p}(\bar{\tau}) \\
\text { s.t. } & \underline{\tau} \geq 0, \quad \bar{\tau} \geq \tau_{k} \\
& \theta_{H} \geq U^{*}\left(\underline{\tau}, w_{1}\right)-U^{*}\left(\bar{\tau}, w_{1}\right) \geq \theta_{L} \quad(\mathrm{BC}),
\end{array}
$$

It is easily verified that, at an optimum, only the constraint $U^{*}\left(\underline{\tau}, w_{1}\right)-$ $U^{*}\left(\bar{\tau}, w_{1}\right) \geq \theta_{L}$ is binding. Optimal taxes are given as $\underline{\tau}^{* *}=0$ and $\bar{\tau}^{* *}=\tau_{1 L}$. Expected utilitarian welfare under rule $Q^{1}$ equals:

$$
\begin{aligned}
E W^{1}= & \left(p_{L L}+p_{L H}\right)\left(U^{*}\left(0, w_{1}\right)+U^{*}\left(0, w_{2}\right)\right) \\
& \left(p_{H L}+p_{H H}\right)\left(U^{*}\left(\tau_{1 L}, w_{1}\right)+U^{*}\left(\tau_{1 L}, w_{2}\right)\right) \\
& +p_{H L}\left(\theta_{L}+\theta_{H}\right)+2 p_{H H} \theta_{H} .
\end{aligned}
$$

Rule $Q^{2}$ : Under provision rule $Q^{2},\left(\mathrm{IC}_{1}\right)$ requires $V_{1}\left(\theta_{H}, \theta_{L}\right)=V_{1}\left(\theta_{L}, \theta_{L}\right)$ and $V_{1}\left(\theta_{H}, \theta_{H}\right)=V_{1}\left(\theta_{L}, \theta_{H}\right)$, or equivalently $\underline{\tau}:=\tau\left(\theta_{L}, \theta_{L}\right)=\tau\left(\theta_{H}, \theta_{L}\right)$ and $\bar{\tau}:=\tau\left(\theta_{H}, \theta_{H}\right)=\tau\left(\theta_{L}, \theta_{H}\right)$. The planner's problem can be written as:

$$
\begin{array}{lll}
\max _{\bar{\tau}, \underline{\tau}} & \left(p_{L L}+p_{H L}\right) W_{p}(\underline{\tau})+\left(p_{L H}+p_{H H}\right) W_{p}(\bar{\tau}) \\
\text { s.t. } & \underline{\tau} \geq 0, \quad \bar{\tau} \geq \tau_{k} & (\mathrm{BC}), \\
& \theta_{H} \geq U^{*}\left(\underline{\tau}, w_{2}\right)-U^{*}\left(\bar{\tau}, w_{2}\right) \geq \theta_{L} \quad\left(\mathrm{IC}_{2}\right) .
\end{array}
$$


By definition of Scenario 2, the optimal tax policy $\tau=0$ if $Q=0$ and $\tau=\tau_{k}$ if $Q=1$ is incentive compatible, and expected utilitarian welfare becomes:

$$
\begin{aligned}
E W^{2}= & \left(p_{L L}+p_{H L}\right)\left(U^{*}\left(0, w_{1}\right)+U^{*}\left(0, w_{2}\right)\right) \\
& +\left(p_{L H}+p_{H H}\right)\left(U^{*}\left(\tau_{k}, w_{1}\right)+U^{*}\left(\tau_{k}, w_{2}\right)\right) \\
& +p_{L H}\left(\theta_{L}+\theta_{H}\right)+2 p_{H H} \theta_{H} .
\end{aligned}
$$

Rule $Q^{i}$ : The solution to this problem has been characterized in Lemma 3, i.e. if $\theta_{H} \geq U^{*}\left(0, w_{2}\right)-U^{*}\left(\tau_{1 L}\right)$, expected utilitarian equals:

$$
\begin{aligned}
E W^{i}= & p_{L L}\left(U^{*}\left(0, w_{1}\right)+U^{*}\left(0, w_{2}\right)\right) \\
& +\left(1-p_{L L}\right)\left(U^{*}\left(\tau_{1 L}, w_{1}\right)+U^{*}\left(\tau_{1 L}, w_{2}\right)\right) \\
& +\left(p_{L H}+p_{H L}\right)\left(\theta_{L}+\theta_{H}\right)+2 p_{H H} \theta_{H} .
\end{aligned}
$$

If, to the contrary, $\theta_{H}<U^{*}\left(0, w_{2}\right)-U^{*}\left(\tau_{1 L}, w_{2}\right)$, then, if a solution to the planner's problem exists, expected utilitarian welfare equals:

$$
\begin{aligned}
E W^{i}= & p_{L L}\left(U^{*}\left(\tau_{L L}, w_{1}\right)+U^{*}\left(\tau_{L L}, w_{2}\right)\right) \\
& +\left(1-p_{L L}\right)\left(U^{*}\left(\tau_{H H}, w_{1}\right)+U^{*}\left(\tau_{H H}, w_{2}\right)\right) \\
& +\left(p_{L H}+p_{H L}\right)\left(\theta_{L}+\theta_{H}\right)+2 p_{H H} \theta_{H} .
\end{aligned}
$$

Rule $Q \equiv 1$ : Under provision rule $Q \equiv 1$, expected utilitarian welfare equals:

$$
\begin{aligned}
E W^{Q \equiv 1}= & U^{*}\left(\tau_{k}, w_{1}\right)+U^{*}\left(\tau_{k}, w_{2}\right) \\
& +2 p_{L L} \theta_{L}+\left(p_{L H}+p_{H L}\right)\left(\theta_{L}+\theta_{H}\right)+2 p_{H H} \theta_{H} .
\end{aligned}
$$

The proof of Proposition 2 is now established by the following claims:

Claim 1. Under scenario $2, Q \equiv 0$ and $Q^{i \prime}$ are strictly dominated by $Q^{2}$.

$$
\begin{aligned}
E W^{2}> & \left(1-p_{H H}\right)\left(U^{*}\left(0, w_{1}\right)+U^{*}\left(0, w_{2}\right)\right) \\
& +p_{H H}\left(U^{*}\left(\tau_{k}, w_{1}\right)+U^{*}\left(\tau_{k}, w_{2}\right)+2 \theta_{H}\right) .
\end{aligned}
$$

Under Scenario 2, the right hand side is strictly larger than $E W^{i^{\prime}}$ and $E W^{Q \equiv 0}$. 
Claim 2. If $\theta_{H}<U^{*}\left(0, w_{2}\right)-U^{*}\left(\tau_{1 L}, w_{2}\right)$, then $E W^{i^{\prime}}=E W^{i}$ : Using the equations $\theta_{H}=U^{*}\left(\tau_{L L}, w_{2}\right)-U^{*}\left(\tau_{H H}, w_{2}\right)$ and $U^{*}\left(\tau_{L L}, w_{1}\right)-U^{*}\left(\tau_{H H}, w_{1}\right)=$ $\theta_{L}$ to substitute for $\theta_{L}$ and $\theta_{H}$ in the expressions for $E W^{i^{\prime}}$ and $E W^{i}$ in equations (12) and (8) reveals that $E W^{i^{\prime}}=E W^{i}$.

Claim 3. If $\theta_{H}<U^{*}\left(0, w_{2}\right)-U^{*}\left(\tau_{1 L}, w_{2}\right)$, then $E W^{i}<E W^{2}$ : This is a direct consequence of Claims 1 and 2 .

Claim 4. If $\theta_{H} \geq U^{*}\left(0, w_{2}\right)-U^{*}\left(\tau_{1 L}, w_{2}\right)$, then $E W^{i} \geq E W^{1}$ with equality if and only if $\theta_{H}=U^{*}\left(0, w_{2}\right)-U^{*}\left(\tau_{1 L}, w_{2}\right)$ : To see this, use equations (11) and (9), as well as the definition of $\tau_{1 L}$, to derive:

$$
E W^{i}-E W^{1}=p_{L H}\left(U^{*}\left(\tau_{1 L}, w_{2}\right)+\theta_{H}-U^{*}\left(0, w_{2}\right)\right) .
$$

Claim 5. If $\theta_{H}<U^{*}\left(0, w_{2}\right)-U^{*}\left(\tau_{1 L}, w_{2}\right)$, then $E W^{1}<E W^{2}$ : Equations (9) and (10) imply:

$$
\begin{aligned}
& E W^{2}-E W^{1}= \\
& p_{H L}\left(U^{*}\left(0, w_{2}\right)-U^{*}\left(\tau_{1 L}, w_{2}\right)-\theta_{H}\right) \\
& +p_{L H}\left(U^{*}\left(\tau_{k}, w_{1}\right)+U^{*}\left(\tau_{k}, w_{2}\right)+\theta_{L}+\theta_{H}-U^{*}\left(0, w_{1}\right)-U^{*}\left(0, w_{2}\right)\right) \\
& +p_{H H}\left(U^{*}\left(\tau_{k}, w_{1}\right)+U^{*}\left(\tau_{k}, w_{2}\right)-U^{*}\left(\tau_{1 L}, w_{1}\right)-U^{*}\left(\tau_{1 L}, w_{2}\right)\right) .
\end{aligned}
$$

All terms in this sum are strictly positive under Scenario 2.

Claim 6. $E W^{2}-E W^{Q \equiv 1}$ may become positive or negative, depending on the prior probabilities: From equations (13) and (10):

$$
\begin{aligned}
& E W^{2}-E W^{Q \equiv 1}= \\
& p_{L L}\left(U^{*}\left(0, w_{1}\right)+U^{*}\left(0, w_{2}\right)-U^{*}\left(\tau_{k}, w_{1}\right)-U^{*}\left(\tau_{k}, w_{2}\right)-2 \theta_{L}\right) \\
& +p_{H L}\left(U^{*}\left(0, w_{1}\right)+U^{*}\left(0, w_{2}\right)-U^{*}\left(\tau_{k}, w_{1}\right)-U^{*}\left(\tau_{k}, w_{2}\right)-\theta_{L}-\theta_{H}\right) .
\end{aligned}
$$

Under Scenario 2, the first term is positive and the second is negative.

Claim 7. Let $\theta_{H} \geq U^{*}\left(0, w_{2}\right)-U^{*}\left(\tau_{1 L}, w_{2}\right) . E W^{2}-E W^{i}$ and $E W^{Q \equiv 1}-E W^{i}$ may become positive or negative, depending on the prior probabilities: From 
equations (10), (11) and (13), one derives:

$$
\begin{aligned}
& E W^{2}-E W^{i}= \\
& p_{H L}\left(U^{*}\left(0, w_{2}\right)-U^{*}\left(\tau_{1 L}, w_{2}\right)-\theta_{H}\right) \\
& +\left(p_{L H}+p_{H H}\right)\left(U^{*}\left(\tau_{k}, w_{1}\right)+U^{*}\left(\tau_{k}, w_{2}\right)-U^{*}\left(\tau_{1 L}, w_{1}\right)-U^{*}\left(\tau_{1 L}, w_{2}\right)\right),
\end{aligned}
$$

and

$$
\begin{aligned}
& E W^{Q \equiv 1}-E W^{i}= \\
& p_{L L}\left(U^{*}\left(\tau_{k}, w_{1}\right)+U^{*}\left(\tau_{k}, w_{2}\right)+2 \theta_{L}-U^{*}\left(0, w_{1}\right)-U^{*}\left(0, w_{2}\right)\right) \\
& +\left(1-p_{L L}\right)\left(U^{*}\left(\tau_{k}, w_{1}\right)+U^{*}\left(\tau_{k}, w_{2}\right)-U^{*}\left(\tau_{1 L}, w_{1}\right)-U^{*}\left(\tau_{1 L}, w_{2}\right)\right) .
\end{aligned}
$$

For both differences the first term is negative and the second is positive. The expressions for $E W^{2}-E W^{Q \equiv 1}, E W^{2}-E W^{i}$ and $E W^{Q \equiv 1}-E W^{i}$ derived above are linear, hence continuous in the probabilities, implying that, for $\theta_{H} \geq U^{*}\left(0, w_{2}\right)-U^{*}\left(\tau_{1 L}, w_{2}\right)$, any of the rules $Q^{2}, Q^{i}$ or $Q \equiv 1$ may yield the maximal level of welfare.

\section{References}

Armstrong, A. and Rochet, J. (1999). Multi-dimensional screening: A user's guide. European Economic Review, 43:959-979.

Atkinson, A. and Stern, N. (1974). Pigou, taxation and public goods. Review of Economic Studies, 41:119-128.

Bergemann, D. and Morris, S. (2005). Robust mechanism design. Econometrica, 73:1771-1813.

Bierbrauer, F. (2005a). Collectively incentive compatible tax systems. Mimeo, Max Planck Institute for Research on Collective Goods, Bonn.

Bierbrauer, F. (2005b). Optimal income taxation and public good provision in a two-class economy. Preprint 2005/25, Max Planck Institute for Research on Collective Goods, Bonn.

Bierbrauer, F. and Sahm, M. (2005). Informative voting and the Samuelson rule. Mimeo, Max Planck Institute for Research on Collective Goods, Bonn and LMU, München.

Boadway, R. and Keen, M. (1993). Public goods, self-selection and optimal income taxation. International Economic Review, 34:463-478. 
Chung, K. and Ely, J. (2004). Foundations of dominant strategy mechanisms. Mimeo, Northwestern University.

Clarke, E. (1971). Multipart pricing of public goods. Public Choice, 11:1733 .

Coate, S. and Morris, S. (1995). On the form of transfers to special interests. Journal of Political Economy, 103:1210-1235.

Cremer, H., Pestieau, P., and Rochet, J. (2001). Direct versus indirect taxation: The design of the tax structure revisited. International Economic Review, 42:781-799.

Gaube, T. (2000). When do distortionary taxes reduce the optimal supply of public goods? Journal of Public Economics, 76:151-180.

Gaube, T. (2005). Financing public goods with income taxation: Provision rules vs. provision levels. International Tax and Public Finance, 12:319334.

Green, J. and Laffont, J. (1977). Characterization of satisfactory mechanisms for the revelation of preferences for public goods. Econometrica, $45: 472-487$.

Groves, T. (1973). Incentives in teams. Econometrica, 41:617-663.

Hellwig, M. (1986). The optimal linear income tax revisited. Journal of Public Economics, 31:163-179.

Hellwig, M. (2003). Public-good provision with many participants. Review of Economic Studies, 70:589-614.

Hellwig, M. (2004). Optimal income taxation, public goods provision and public-sector pricing: A contribution to the foundations of public economics. Preprint 2004/14, Max Planck Institute for Research on Collective Goods, Bonn.

Kalai, E. (2004). Large robust games. Econometrica, 72:1631-1665.

Nava, M., Schroyen, F., and Marchand, M. (1996). Optimal fiscal and public expenditure policy in a two-class economy. Journal of Public Economics, 61:119-137.

Norman, P. (2004). Efficient mechanisms for public goods with use exclusion. Review of Economic Studies, 71:1163-1188.

Persson, T. and Tabellini, G. (2000). Political Economics: Explaining Economic Policy. Cambridge, MA, MIT Press. 
Polo, M. (1998). Electoral competition and political rents. Mimeo, Innocenzo Gasparini Institute for Economic Research, Milan.

Samuelson, P. (1954). The pure theory of public expenditure. Review of Economics and Statistics, 36:387-389.

Sandmo, A. (1998). Redistribution and the marginal costs of public funds. Journal of Public Economics, 70:365-382.

Sheshinski, E. (1972). The optimal linear income-tax. Review of Economic Studies, 39:297-302.

Stiglitz, J. (1982). Self-selection and Pareto-efficient taxation. Journal of Public Economics, 17:213-240.

Svensson, J. (2000). Controlling spending: Electoral competition, polarization and endogenous platforms. Mimeo, Institute for International Economic Studies, Stockholm University.

Wilson, J. (1991). Optimal public good provision with limited lump sum taxation. American Economic Review, 81:153-166. 